\title{
Correspondence
}

\section{Attitudes of Staff and Patients to Psychiatric Admission Wards}

DeAR SIR,

When I started to read this paper (Bulletin, Feb 1980, pp 22-25) I was puzzled by its use of anonymity for the author and hospital concerned; the results revealed nothing shameful. I became more worried when I realized that there was to be no attempt to describe the three wards sampled, even though the attitudes measured in any unit and the nature of its structure and functions are intimately interrelated. Moos and his colleagues at Stanford's Social Ecology Laboratory have for many years been systematically investigating these relationships. ${ }^{1}$

My main criticism, however, is one of the paper's implicit assumption that the wards surveyed are 'typical' admission units, so permitting the use of the results to make general recommendations. I particularly challenge whether these findings can be said to give any support to the suggestion that disturbed patients should be admitted to single-sex wards staffed by uniformed personnel (except, perhaps, in the actual hospital studied). I have, for example, recently described an acute admission unit (Street Ward Community, Fulbourn Hospital, Cambridge) which, by using a therapeutic community culture, contains all the disturbed patients admitted from its 'sector' in a mixed sex, uniformfree, open setting, without any seclusion room or locked ward back-up. ${ }^{2}$

Before recommendations concerning the optimum organization of any type of unit can be made, it is necessary first to learn how staff and patient attitudes are shaped by various ward programmes, styles of leadership, etc, and how these attitudes in turn affect function and results.

\section{G. P. PULlEN} Consultant Psychiatrist

Littlemore Hospital. Oxford.

\section{REFERENCES}

1 Moos, R.H. (1976) The Human Context: Environmental Determinants of Behaviour. New York, Wiley. Interscience.

2 Pullen, G. P. (1980) Communal medication. International Journal of Therapeutic Communities, $1,1$.

\section{Rotational Training Schemes}

Dear Sir,

I read with interest the description of the two rotational training schemes in the December issue of the Bulletin, $p$. 190. One cannot dispute that they are examples of good current practice, but I am apprehensive that their standard will become the 'norm' which every hospital is required to meet, even though local factors make it impossible to do so.

There are many similarities between Exeter, its catchment area and the area covered by the Cleveland Area Health Authority. We serve a similar population and have similar Consultant staffing levels, with the addition of a Consultant in Adolescent Psychiatry who runs a sub-regional unit, and a Consultant in Forensic Psychiatry who runs an interim secure unit and will become responsible for the Regional Secure Unit which opens later this year, and we offer, I think, a wide range of experience.

St Luke's Hospital serves rather more than half of the catchment area and has recently been placed in Category 'A', whilst the two DGH units, which serve the rest of the area, have been placed in Category 'P'. It has been made clear that if we do not establish a Cleveland Rotational Training Scheme, the DGH units will lose approval and St Luke's will shortly follow them into oblivion.

My colleagues are eager to establish a rotational scheme, but between us we muster a grand total of two Registrars and one Senior Registrar, which establishment we have sought to increase, only to be turned down by the Central Manpower Committee, even in respect of a Registrar for the Regional Secure Unit for which we have funds. It must be admitted that we have some SHOs, but in a situation where the majority would have to remain in that grade for $3 \frac{1}{2}$ years we cannot attract candidates who are seriously pursuing a career in psychiatry.

I would be grateful if someone could tell us, in these circumstances, how we can meet the standard set by Exeter. I strongly suspect that the only realistic answer is a compulsory redistribution of Registrars away from those areas where they are to be found in plenty, but I doubt if the Consultants therein are prepared to make the ultimate sacrifice of giving up a Registrar. Still less do I believe that there is a Collegiate will to force them to do so.

Thus we face the prospect of unapproved hospitals in Cleveland, to which Consultants will not come and where services will then deteriorate to a point that will demand an inquiry, at enormous cost, by the DHSS in which those Consultants foolish enough to stay will be criticized for failure to show adequate leadership.

Needless to say, I am considering the possibility of an early retirement.

St Luke's Hospital,

JOHN BLACKBURN

Middlesbrough,

Cleveland, TS4 3AF.

DEAR SIR,

\section{Cuts in the National Health Service}

Mr Patrick Jenkin's letter to the President published in the Bulletin (February 1980) would be reassuring if only it matched the state of affairs seen in the District Psychiatric Services. 
My understanding of the position is that an inflationproofed growth of 3 per cent nationally is based on a forward-looking estimate of inflation. If this estimate is deficient by, say, $2 \frac{1}{2}$ per cent, and I understand that this is currently so, then the 3 per cent growth is reduced immediately to $\frac{1}{2}$ of 1 per cent. The under-estimate in one year may well be rectified in a subsequent year, but this is small recompense if in that subsequent year the prospect for inflation is again underestimated. In such circumstances the deficiency is perpetuated from year to year.

If, by further mischance, real inflation is greater than anticipated inflation, say, in the instance given, if it is greater than 3 per cent, then any 'growth' is reduced to a negative value. Furthermore, if outside contractors to the Health Service look ahead and inflation-proof their estimates, the real value of any hedge against inflation is further decreased by their anticipated proofing.

In addition, the Health Service requires to keep pace with the growing population at, I understand, a rate of 1 per cent per annum. If there is a real inflation-proofed growth of $\frac{1}{2}$ per cent per annum, then relatively there is a recession of $\frac{1}{2}$ per cent against the 1 per cent needed to keep pace with population.

Nationally agreed priorities have to be implemented by Districts in the face of difficulties such as the above. Within cash limits, one man's priority is another man's cut, and in these circumstances it takes a firm will to give the psychiatric services, the elderly and the mentally handicapped their due precedence. All too often it just does not happen.

In these matters I would be happy to be shown that my views are wrong, as it would give me some heart in contributing to planning for a projected 65 per cent increase

\section{Under Discussion}

\section{Closures in the Health Service}

The way in which lack of funds in the Health Service is leading to closure of psychiatric facilities of various kinds needs careful watching by those closest to the institutions affected. Closure or down-grading may be decided for a multiplicity of reasons, of which lack of money this year is only one. Sometimes the closure is less total than it appears (i.e. transfer of the work or staff elsewhere). In some cases the arguments about closure are bound to be fought locally with local knowledge; but in a few the case may have national implications. In these latter cases the College as a whole will want to act, possibly by making representations to the Secretary of State*, who might perhaps accept that facilities with a supra-regional function should have some special funding beyond that which their Health Authority can afford. Thus the John Conolly Hospital in Birmingham may

-A letter from the Secretary of State outlining the Government's position as regards the closures was published in the Bulletin, February, p. 32, but see also the letter from G. E. Langley above. in the very elderly population of this District in the next ten years.

Exe Vale Hospital

G. E. LANGLEY

Exminster

Exeter EX6 8AB

\section{Specialist Posts in Commaunity Psychiatry}

DeAR SIR,

The Social and Community Psychiatry Section of the College has set up a Working Party, of which I am Convenor, to examine the possibility of specialist posts in community psychiatry. Associated with this question is the need (if any) for specialist training. Such posts might include liaison with social services, preventive work, evaluation, and training of other professions.

It would greatly assist the Working Party if it could know of any such arrangements which now exist. I would therefore be grateful to hear from any colleagues who have specified sessions for community work or liaison with social services, or alternatively, de facto arrangements which have proved to be successful. Also, any current arrangements for training in this area of work would be of great interest.

In addition, the Working Party would be glad to hear views on the questions it is studying from other colleagues who have no specified arrangements of this kind. One relevant question is how many established consultants might want to transfer to such posts, if they existed.

Hope Hospital,

Hugh L. Freeman Eccles Old Road,

Salford M6 8HD be a local matter; the closure of the neuropathology department at Runwell is a transfer of work to a difierent site, not the closing down of one of the very few neuropathological opportunities in Britain; while the Henderson Hospital, also threatened, has some claim to be considered a national asset.

\section{Reeruitment to Psychiatry}

The College in conjunction with APIT and the Association of University Teachers of Psychiatry is planning a conference in 1981 on recruitment to psychiatry and its implications for education and training. Various working parties are to meet and prepare reports on particular aspects of this theme for submission to the Conference, e.g. future pattern of psychiatric services, relation between psychiatry, social work, clinical services, training settings, psychiatric teaching and status in the medical school.

\section{ONLOOKER}

